\title{
50th ANNIVERSARY OF THE JOURNAL OF THEORETICAL AND APPLIED MECHANICS
}

\author{
doi: 10.7546/JTAM.50.20.01.01
}

Established in 1970, the Journal of Theoretical and Applied Mechanics (JTAM) publishes valuable papers in the different fields of Theoretical and Applied Mechanics, namely General, Fluid and Solid Mechanics, including interdisciplinary areas. During its half century evolution JTAM succeeded to create, conserve and develop well established traditions, becoming a competent and informative source of knowledge for the mechanical community.

To achieve this we were helped by many authors and reviewers from different countries. It is our pleasure to express sincere gratitude to all of them.

We hope that JTAM will keep its high level in the years that follow.

Editorial Board.

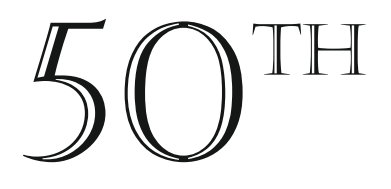

